Marquette University

e-Publications@Marquette

College of Nursing Faculty Research and

Publications

Nursing, College of

$5-1-2008$

Factors Associated With Perceived Burden, Resourcefulness, and Quality of Life in Female Family Members of Adults With Serious Mental Illness

Jaclene Zauszniewski

Case Western Reserve University

Abir Bekhet

Marquette University, abir.bekhet@marquette.edu

M. Jane Suresky

Case Western Reserve University

Accepted version. Journal of the American Psychiatric Nurses Association, Vol. 14, No. 2 (2008): 125-135. DOI. (C) 2008 by American Psychiatric Nurses Association. Used with permission. Abir K. Behket was affiliated with the Psychiatric and Mental Health Nursing, Alexandria University, Faculty of Nursing, Alexandria, Egypt at the time of publication. 
Marquette University

\section{e-Publications@Marquette}

\section{Nursing Faculty Research and Publications/College of Nursing}

This paper is NOT THE PUBLISHED VERSION; but the author's final, peer-reviewed manuscript. The published version may be accessed by following the link in the citation below.

Journal of the American Psychiatric Nurses Association, Vol. 14, No. 2 (2008): 125-135. DOI. This article is (C) SAGE Publications and permission has been granted for this version to appear in ePublications@Marquette. SAGE Publications does not grant permission for this article to be further copied/distributed or hosted elsewhere without the express permission from SAGE Publications.

\section{Contents}

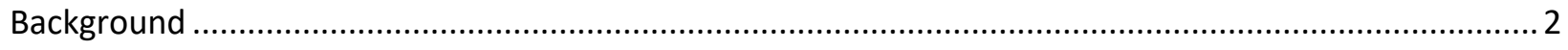

Keywords: caregiver burden; stigma by association; resourcefulness; quality of life; mental illness.......... 2

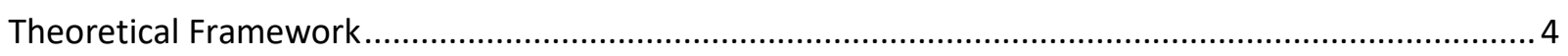

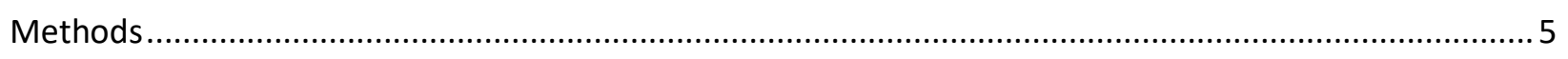

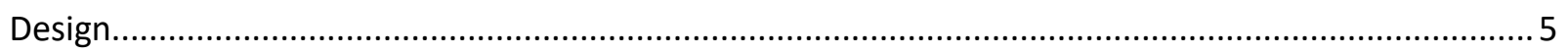

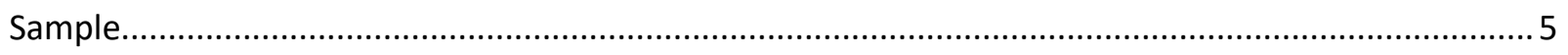

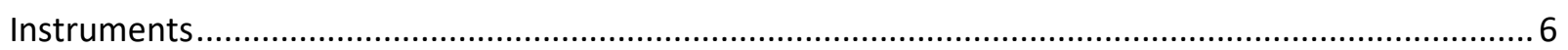

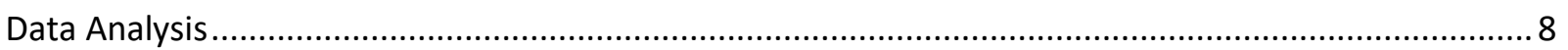

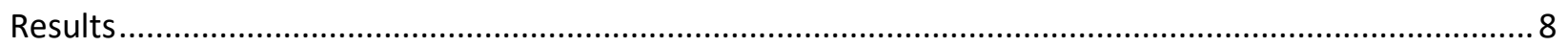

Associations Between Contextual Variables and Process Regulators …............................................ 8

Associations Between Contextual Variables and Resourcefulness ................................................. 10

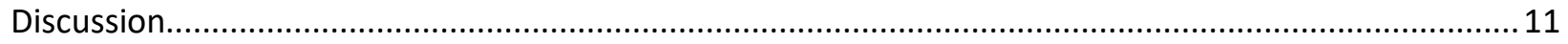

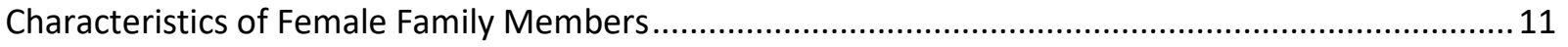

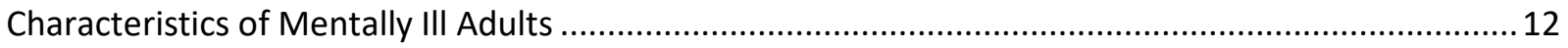

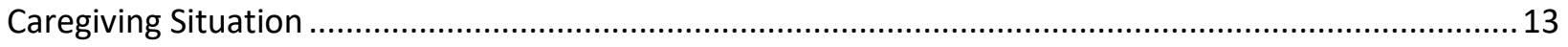

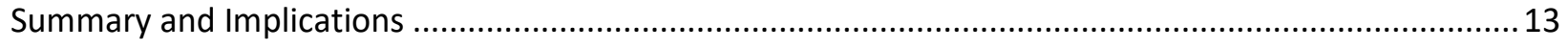

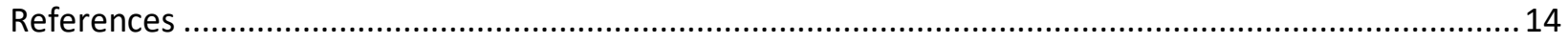




\title{
Factors Associated with Perceived Burden, Resourcefulness, and Quality of Life in Female Family Members of Adults with Serious Mental Illness
}

\author{
Jaclene A. Zauszniewski
}

Frances Payne Bolton School of Nursing, Case Western Reserve University, Cleveland, $\mathrm{OH}$ Abir K. Bekhet

Faculty of Nursing, Alexandria University, Alexandria, Egypt

M. Jane Suresky

Frances Payne Bolton School of Nursing, Case Western Reserve University, Cleveland, $\mathrm{OH}$

\section{Background}

Each year, 54 million American adults are affected by serious mental illness. Most of these persons depend on female family members for support or assistance, and unless these women are resourceful, they may experience considerable burden, stigma by association, depressive thoughts, and poor quality of life. OBJECTIVE: In this study, we examined the associations between characteristics of female family members (age, race, education), adults with serious mental illness (age, diagnosis), and the family situation (relationship, living arrangements, care provided) and caregivers' burden, stigma, depressive cognitions, resourcefulness, and quality of life. STUDY DESIGN: In this descriptive, crosssectional study, a convenience sample of 60 female relatives of adults with serious mental illness provided demographic information and completed established measures of the study variables. RESULTS: We discuss associations between contextual variables and process regulators, resourcefulness, and quality of life. CONCLUSIONS: The results highlight the importance of targeting interventions for caregivers of adults with serious mental illness who are parents, caregivers of younger seriously mentally ill persons in earlier stages of diagnosis, and caregivers of persons who have bipolar disorder.

Keywords: caregiver burden; stigma by association; resourcefulness; quality of life; mental illness

It is estimated that $5 \%$ to $7 \%$ of adults in the United States, or 10 to 17.5 million persons, experience serious mental illness (SMI) each year, defined by U.S. federal regulations as a diagnosed mental disorder that affects one's daily functioning at work, at home, or in social 
relationships (U.S. Department of Health and Human Services, 2003). Mental illness is a broad label for psychiatric disorders that may include symptoms of emotional instability, behavioral problems, and cognitive dysfunction or impairment. These disorders include schizophrenia, bipolar disorder, panic disorder, and obsessive-compulsive disorders (American Psychiatric Association, 2000).

Over the past few decades, deinstitutionalization movements have decreased reliance on institutions to provide care for mentally ill persons, and families, by choice or necessity, have taken responsibility for caring for their mentally ill family members (KohnWood \& Wilson, 2005; Wynaden et al., 2006). The majority of caregivers for persons with mental illness are women; Kohn-Wood and Wilson (2005) noted that $69 \%$ of caregivers of seriously mentally ill persons in their study were females, and Tung and Gillett (2005) reported that $56.6 \%$ of family caregivers were women. The burden of caring for a mentally ill family member is considerable (Stengard, 2002; Takano \& Arai, 2005; Tsang, Tam, Chan, \& Cheung, 2003). Furthermore, female relatives of seriously mentally ill persons perceive themselves as having more burden than do males and judge their quality of life significantly worse than the general population (Fleischman \& Klupp, 2004).

Caregiver burden is affected by disruptive behaviors of the mentally ill person, changes in household routines, strained social relationships, lack of social support, deteriorating finances, diminished opportunity for leisure, exhaustion, and the stigma associated with mental illness, termed stigma by association (Sibitz, Amering, Kramer, Griengl, \& Katschnig, 2002; Stengard, 2002; Veltman, Cameron, \& Stewart, 2002). In addition to experiencing caregiver burden, female family caregivers may experience negative cognitions or thinking patterns that can precede clinical depression (Beevers, Wells, \& Miller, 2007).

Indeed, caregiver burden has been associated with depressed mood (Lu \& Wykle, 2007) and depressive symptoms (Perlick et al., 2007). Furthermore, a large percentage of female spouses of mentally ill persons have been found to suffer from affective disorders: $38.8 \%$ suffer from depressive disorders, $23.9 \%$ from anxiety disorders, and 20.9\% from somatoform disorders (Wittmund, Wilms, Mory, \& Angermeyer, 2002).

Mental disorders are more prevalent among African Americans than Caucasians, and African Americans tend to enter treatment for mental problems at later, more advanced stages of illness, are misdiagnosed more often, are diagnosed with an SMI more often, and discontinue treatment for mental conditions sooner than Caucasians (Anglin, Link, \& Phelan, 2006; Nelson, 2006). All of these factors may contribute to the feelings of burden and stigma reported by African American family members of mentally ill persons (Anglin et al., 2006; Nelson, 2006). However, African American family caregivers of adults with SMI have been little studied. Therefore, in this study, we examined both Caucasian and African American women who were caregivers of adults with SMI.

Positive cognitions and resourcefulness are significant predictors of better quality of life among caregivers (Zauszniewski, Picot, Roberts, Debanne, \& Wykle, 2005). Resourcefulness may be defined as a collection of cognitive and behavioral skills that are used to maintain independence in daily tasks despite the presence of adversity (Rosenbaum, 1990) and to obtain 
assistance from others when unable to function independently (Nadler, 1990). Personal and social resourcefulness skills are complementary, can fluctuate over time, and are equally important for optimal quality of life (Zauszniewski, 2006). Studies of caregivers have provided evidence of the importance of resourcefulness in promoting independence and enhancing daily functioning (Rosswurm, Larrabee, \& Zhang, 2002; Zauszniewski et al., 2005). However, factors affecting the resourcefulness of family members of mentally ill persons have not been examined. In this study, we examined factors within the female family member, the adult with SMI, and the caregiving situation that might affect resourcefulness and the quality of life of caregivers of adults with SMI.

\section{Theoretical Framework}

Zauszniewski's (2006) middle-range theory of resourcefulness and quality of life provided the framework for the study. This theory is based on the conceptualization of two forms of resourcefulness (personal and social) that affect quality of life, defined as an individual's subjective sense of well-being and operationalized as perceptions of physical and mental health (Haas, 1999; Ware, Kosinski, \& Keller, 1996). Other major constructs of the theory are contextual factors and intervening variables, called "process regulators." According to this theoretical model, contextual factors may exist within a person or within the person's environment and may influence process regulators and resourcefulness, which in turn affect quality of life. Contextual factors for female family members of adults with SMI include characteristics of the women, characteristics of the adult with SMI, and characteristics of the caregiving situation.

According to Zauszniewski's theory, among family female caregivers of adults with SMI, perceived burden, stigma by association, and depressive cognitions may be considered process regulators, or cognitions, perceptions, and emotions that directly influence resourcefulness and quality of life (Zauszniewski, 2006). Thus, according to the theory, contextual factors have direct effects on process regulators, resourcefulness, and quality of life. In addition, contextual factors have indirect effects on resourcefulness through process regulators and indirect effects on quality of life through resourcefulness. However, in the study described here, we focused on examining the direct effects of the contextual factors on process regulators (perceived burden, stigma, and depressive cognitions), resourcefulness (personal and social), and quality of life (physical and mental health).

Some researchers have examined associations between the characteristics of family caregivers of elders and their burden, cognitions, resourcefulness, and quality of life. Investigators have looked at the impact of caregiver age, race/ethnicity, and level of education on burden (DeFrias, Tuokko, \& Rosenberg, 2005; Keir et al., 2006; McCullagh, Brigstocke, Donaldson, \& Kalra, 2005; Papastavrou, Kalokerinou, Papacostas, Tsangari, \& Sourtzi, 2007; Zauszniewski et al., 2005); depressive symptoms, including cognitions (Drentea \& Goldner, 2006; Pinquart \& Sorensen, 2005; Williams, 2005; Zauszniewski et al., 2005); resourcefulness (Gonzalez, 1997; Zauszniewski et al., 2005); and quality of life (Belle et al., 2006; McCullagh et al., 2005; Pinquart \& Sorensen, 2007; Serrano-Aguilar, Lopez-Bastida, \& Yanes-Lopez, 2006). However, few researchers have examined the effects of care recipient characteristics, including their age, diagnosis, and duration of illness (Gonzalez-Salvador, Arango, Lyketsos, \& Barba, 
1999; McCusker, Latimer, Cole, Ciampi, \& Sewitch, 2007; Raina et al., 2004) or the effects of the family situation, including living arrangements, relationship to the ill family member, or type of care provided, on health outcomes of family caregivers (Savage \& Bailey, 2004; Steadman, Tremont, \& Davis, 2007). Many of the studies conducted with caregivers did not include caregivers of persons with mental illness.

In this descriptive study, we examined contextual factors, including characteristics of the female family members of seriously mentally ill adults (age, race/ethnicity, and level of education), characteristics of the mentally ill adults (age, diagnosis, and time since first diagnosed), and characteristics of the family situation (relationship, living arrangements, and care provided) that might affect process regulators (perceived burden, stigma, depressive cognitions), resourcefulness (personal and social), and quality of life (mental and physical health) of caregivers of the mentally ill. The following research questions were addressed within the context of the Resourcefulness and Quality of Life model (Zauszniewski, 2006):

1. Are contextual factors (within the female family member, within the adult with SMI, and within the caregiving situation) associated with process regulators (perceived burden, stigma, and depressive cognitions)?

2. Are contextual factors (within the female family member, within the adult with SMI, and within the caregiving situation) associated with resourcefulness (personal and social)?

3. Are contextual factors (within the female family member, within the adult with SMI, and within the caregiving situation) associated with quality of life indicators (physical and mental health).

\section{Methods}

\section{Design}

Data for this exploratory, descriptive study were obtained as part of a larger cross-sectional study of female family members of adults with SMI.

\section{Sample}

The sample consisted of 60 female family members of adults with SMI (i.e., schizophrenia, bipolar disorder, major depressive disorder, and anxiety disorders). The sample included 30 Caucasian and 30 African American women living in northeastern Ohio. To be included in the study, the female family members had to be between 18 and 65 years of age and able to read and understand English. Notices describing the research were posted in community mental health centers, local churches, and places of business (e.g., grocery stores, department stores, restaurants, coffee houses, bookstores, libraries) and given to support groups for family members of seriously mentally ill persons. Interested family members contacted the researchers to learn more about the study and to schedule an appointment for data collection.

The sample size for this study was based on a power analysis and was adequate for examining (a) descriptive trends reflecting substantial differences $(d=.80)$ by race/ethnicity and other groupings (e.g., education of female family member, diagnosis and relationship with 
adult with SMI, living arrangements, and care provided for adult with SMI) and (b) correlation coefficients $(r=.50)$ between continuous demographic variables (i.e., age of female family member and adult with SMI and years since diagnosis of adult with SMI) and study outcomes (i.e., process regulators, resourcefulness, and quality of life) at a significance level of $\alpha=.05$ and power of B = .80 (Cohen, 1992; Sapnas \& Zeller, 2002). Because the analysis of the multiple contextual factors required several statistical tests, which could result in detecting significant findings that in fact occurred by chance, we considered an $\alpha=.01$ as definitive, whereas the .05 level was cautiously interpreted as being suggestive of trends in the data (Cohen, 1992).

\section{Instruments}

The female family members completed five data collection instruments, including a demographic questionnaire and measures of perceived burden

TABLE 1. Measurement of Contextual Factors in Female Family Members, the Mentally III Adult, and the Caregiving Situation

\begin{tabular}{|c|c|c|}
\hline Category & Contextual Variable & Operationalization \\
\hline Female family member & $\begin{array}{l}\text { Age } \\
\text { Education }\end{array}$ & $\begin{array}{l}\text { In years } \\
\text { Three Categories: } \\
\text { - } \quad \text { High school or less } \\
\text { - } \quad \text { Some college or associate's degree } \\
\text { - } \quad \text { Bachelor's degree or higher }\end{array}$ \\
\hline Adult with serious mental illness & $\begin{array}{l}\text { Race/ethnicity } \\
\text { Age } \\
\text { Years since diagnosis } \\
\text { Mental disorder }\end{array}$ & \begin{tabular}{|cl} 
- & African American or Caucasian \\
- & In years \\
- & In years \\
Open-ended item-coded later as: \\
- & Schizophrenia \\
- & Bipolar disorder \\
- & Depression \\
- & Anxiety disorder \\
\end{tabular} \\
\hline Caregiving Situation & $\begin{array}{l}\text { Relationship } \\
\text { Living arrangements } \\
\text { Care Provided }\end{array}$ & \begin{tabular}{|l} 
Open-ended item-coded later \\
- $\quad$ Mother \\
- $\quad$ Sister \\
- Other (daughter, wife, cousin, aunt) \\
Two categories: \\
- Living with woman family member \\
- Living apart \\
Two categories: \\
- $\quad$ Providing care with daily activities \\
- Not providing direct care
\end{tabular} \\
\hline
\end{tabular}

a. Because only a small number of participants reported clinical depression or anxiety disorder in their family member ( $8 \%$ and $2 \%$, respectively), analyses of study outcomes by diagnosis were conducted only with women family members of persons with schizophrenia and bipolar disorder.

(including stigma), depressive cognitions, resourcefulness, and quality of life. To obtain demographic information, open-ended questions were used; data are shown in Table 1.

Perceived burden was measured by the 27-item Overall Caregiver Burden Scale (Biegel, Milligan, Putnam, \& Song, 1994), which contains four subscales: Stigma, Family Disruption, 
Client Dependence, and Caregiver Strain. Responses are given on a 5-point Likert scale ranging from never (0) to always (4), and scores may range from 0 to 108, with higher scores indicating greater stress experienced by the caregiver (Biegel et al., 1994). Internal consistency estimates have been reported for the total scale $(\alpha=.89)$ and for the stigma subscale $(\alpha=.83)$.

Confirmatory factor analysis revealed four factors reflecting the four dimensions (Biegel et al., 1994). Each subscale has been significantly correlated with the total scale and moderately correlated with other subscales, with correlations ranging from $r=.37$ to $r=.56$ (Biegel et al., 1994). Cronbach's alphas in this study for the total scale and for the stigma subscale were .94 and .89 , respectively, and the stigma subscale was significantly correlated with the total scale $(r$ $=.83, \mathrm{p}<.01)$.

Depressive cognitions were measured by the Depressive Cognition Scale (DCS) (Zauszniewski, 1995, 1997), an eight-item instrument on which respondents use a 6-point Likert scale from strongly agree (5) to strongly disagree (0) to indicate the degree to which a particular statement describes their current thoughts. Each item reflects one depressive cognition (e.g., hopelessness, worthlessness); however, the items are phrased positively so that strong disagreement with an item indicates the presence of a depressive cognition. Scores may range from 0 to 40, and when scoring is reversed, higher scores indicate more depressive cognitions. Scores approaching 40 indicate negative cognitions that may precede clinical depression. In a study of community-dwelling elders, Zauszniewski (1995) found acceptable internal consistency $(\alpha=.78)$, and construct validity was evidenced by significant correlations in the expected direction with measures of depression, resourcefulness, adaptive functioning, and life satisfaction. Confirmatory factor analysis has indicated the presence of a single factor with all item factor loadings exceeding .30 (Zauszniewski, 1997). In a study of African American female caregivers, an alpha of .75 showed internal consistency, and significant correlations with depression and daily hassles scales in the expected directions demonstrated construct validity (Zauszniewski, McDonald, Krafcik, \& Chung, 2002). In this study, Cronbach's alpha for the DCS was .87 .

Resourcefulness was measured by the 28-item Resourcefulness Scale (Zauszniewski, Lai, \& Tithiphontumrong, 2006), which contains items reflecting both personal resourcefulness (16 items) and social resourcefulness (12 items). Subjects indicate the degree to which each item describes their behavior, ranging from extremely nondescriptive (0) to extremely descriptive (5). Questions tapping personal and social resourcefulness, respectively, include "When I am faced with a number of things to do, I usually plan my work" and "When it is hard for me to make a decision, I ask someone to help me think things through." Scores may range from 0 to 140, with higher scores indicating greater resourcefulness (Zauszniewski et al., 2006). Cronbach's alphas of $.83, .79$, and .85 have been found for the total scale and the Personal and Social Resourcefulness subscales, respectively. Construct validity and the presence of the two dimensions of resourcefulness were suggested by confirmatory factor analysis: The 16 items from the Personal Resourcefulness subscale loaded cleanly on one factor, whereas the 12 items from the Social Resourcefulness subscale loaded cleanly on a second factor. No items had crossloadings that exceeded .30. Because personal and social resourcefulness are theoretically related constructs, construct validity was further demonstrated by the substantial intercorrelation between the two subscales $(r=.41, p<.001)$ (Zauszniewski et al., 2006). In this 
study, Cronbach's alphas for the Personal and Social Resourcefulness subscales and the Total Resourcefulness scale were $.80, .73$, and .82 , respectively.

Quality of life was measured by the 12-item Short Form Health Survey (SF-12) (Ware et al., 1996), which contains two subscales: Physical Health and Mental Health. The 12 items comprising the instrument are weighted to yield scores on both subscales. Both subscales have demonstrated internal consistency reliability, with Cronbach's alphas exceeding .70 (Luo et al., 2003), and there is published evidence of criterion validity with the SF-36 (Müller-Nordhorn, Roll, \& Willich, 2004) as well as reported evidence of sensitivity to change over time and in response to intervention (Müller-Nordhorn et al., 2004; Salyers, Bosworth, \& Swanson, 2000). Cronbach's alpha for the SF-12 was not assessed in this study because a regressionbased algorithm was used to compute the scores for mental and physical health, as suggested by Ware et al. (1996).

\section{Data Analysis}

We used descriptive statistics, including means, standard deviations, and ranges, to characterize the female family members and the adults with SMI as well as the distribution of process regulators, resourcefulness, and quality of life indicators. We used independent t tests or oneway analyses of variance to examine differences by race/ethnicity, educational level, diagnosis, relationship to adult with SMI, living arrangements, and care provided. We used Pearson's correlations to examine relationships between age (of female family member or adult with SMI) and years since diagnosis and measures of process regulators, resourcefulness, and quality of life.

\section{Results}

The mean age of the 60 female family members was 46 years. There were 30 Caucasian and 30 African American women. Half of the sample completed some college or an associate degree, and most of them were mothers of adults with SMI. The average age of the mentally ill family member was 38 years. Diagnoses included schizophrenia, bipolar disorder, major depression, and panic disorder, and the average number of years since the family member was diagnosed was about 11 years. The majority of the women lived in the same household and provided care for or assisted their mentally ill family member with basic daily needs. Table 2 displays more detailed information about the demographic characteristics of the 60 women and their mentally ill family members.

\section{Associations Between Contextual Variables and Process Regulators}

As shown in Table 3, Caucasian female family members reported greater burden than African Americans, $t(1,58)=2.71, p<.01$. However, there were no significant differences between Caucasians and African Americans in terms of stigma and depressive cognitions. Age and education of the female family member were not associated with any of the process regulators (perceived burden, stigma, and depressive cognitions). 
TABLE 2. Characteristics of Female Family Members, Adults With Serious Mental Illness (SMI), and Caregiving Situation

\begin{tabular}{|c|c|}
\hline \multirow{2}{*}{\begin{tabular}{|l|} 
Contextual Variables \\
Characteristics of female family members \\
\end{tabular}} & Descriptive Statistics for Sample \\
\hline & \\
\hline Age, mean years (SD) & $46.28(11.71)$ \\
\hline \multicolumn{2}{|l|}{ Race/ethnicity, \% } \\
\hline - Caucasian & 50 \\
\hline - African American & 50 \\
\hline \multicolumn{2}{|l|}{ Education, \% } \\
\hline - High school or less & 23 \\
\hline - Some college or associate's degree & 50 \\
\hline - Bachelor's degree or higher & \\
\hline Characteristics of SMI adult & 27 \\
\hline \multicolumn{2}{|l|}{ Age of SMI adult, mean years (SD) } \\
\hline Years since diagnosis, mean (SD) & $37.75(13.96)$ \\
\hline \multicolumn{2}{|l|}{ Diagnosis, \% } \\
\hline - Schizophrenia & \\
\hline - Bipolar disorder & 45 \\
\hline - Major depression & 45 \\
\hline - Panic disorder & 8 \\
\hline Characteristics of caregiving situation & 2 \\
\hline Relationship to SMI adult, \% & \\
\hline - Mother & 40 \\
\hline - Sister & $\begin{array}{l}40 \\
23\end{array}$ \\
\hline $\begin{array}{l}\text { - Other (aunt, wife, daughter, } \\
\text { cousin) }\end{array}$ & \\
\hline Living arrangements, \% & 37 \\
\hline$\bullet \quad$ Same household & 40 \\
\hline - Separate households & 60 \\
\hline Care provision, $\%$ & \\
\hline - Assistance with daily activities & \\
\hline - No direct care & 68 \\
\hline & 32 \\
\hline
\end{tabular}

Greater burden was significantly correlated with younger age of the mentally ill adult $(r=-.32$, $\mathrm{p}<.01$ ). However, neither stigma nor depressive cognitions were correlated with the age of the mentally ill adult. Greater burden was found in female family members of adults with bipolar disorder, $\mathrm{t}(1,52)=-2.95, \mathrm{p}<.01$, than in family members of adults with schizophrenia. Stigma was also greater in female family members of adults with bipolar disorder, $t(1,52)=-2.86, p<$ .01. Depressive cognitions were greater in female family members of adults with schizophrenia than in family members of adults with bipolar disorder, $t(1,52)=-2.74, p<.01$. Years since diagnosis were not correlated with any of the process regulators (perceived burden, stigma, or depressive cognition), as shown in Table 3. 
Mothers of mentally ill adults reported greater burden, $F(2,59)=7.53, p<.001$, and stigma, $F(2,59)=3.06, p<.05$, than did sisters, daughters, or wives, and sisters reported more depressive cognitions, $F(2,59)=3.56, p<.05$, than did mothers, daughters, or wives. Living with the mentally ill person, $t(1,58)=2.01 p<.05$, and providing care for him or her, $t(1,58)=-$ $2.79, p<.01$, were associated with greater burden. However, living arrangements and care provision were not correlated with stigma or depressive cognitions, as shown in Table 3.

\section{Associations Between Contextual Variables and Resourcefulness}

Neither age nor race/ethnicity nor level of education of the female family members was associated with their personal or social resourcefulness. Increasing age of the mentally ill person was associated with greater personal resourcefulness $(r=.32, p<.01)$ in the female family member, as was longer time since diagnosis $(r=.35, p<.01)$. Female family members of adults with schizophrenia had more personal resourcefulness, $t(1,52)=4.19, p<.01$, and more social resourcefulness, $\mathrm{t}(1,52)=2.62, \mathrm{p}<.01$, than did family members of adults with bipolar disorder.

Sisters of mentally ill persons reported more social resourcefulness than did mothers, daughters, or wives, $F(2,59)=-3.16, p<.05$. However, there were no significant differences in personal resourcefulness. Finally, there were no significant differences in personal or social resourcefulness between female family members who lived with the mentally ill person and those who lived apart or between those who provided care/assistance to their mentally ill family member and those who did not.

TABLE 3. Associations Between Contextual Factors and Process Regulators, Resourcefulness, and Quality of Life Outcomes

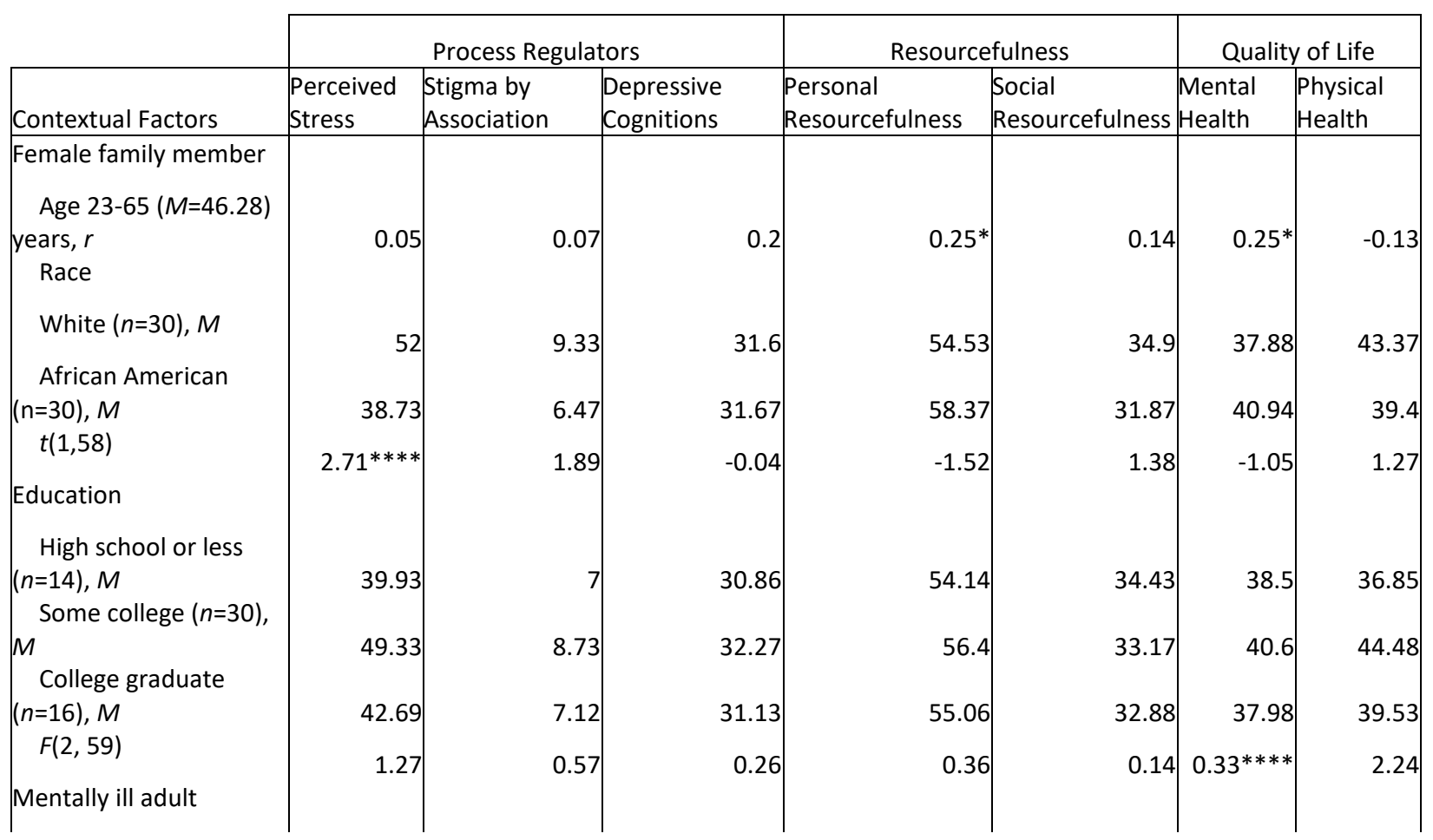




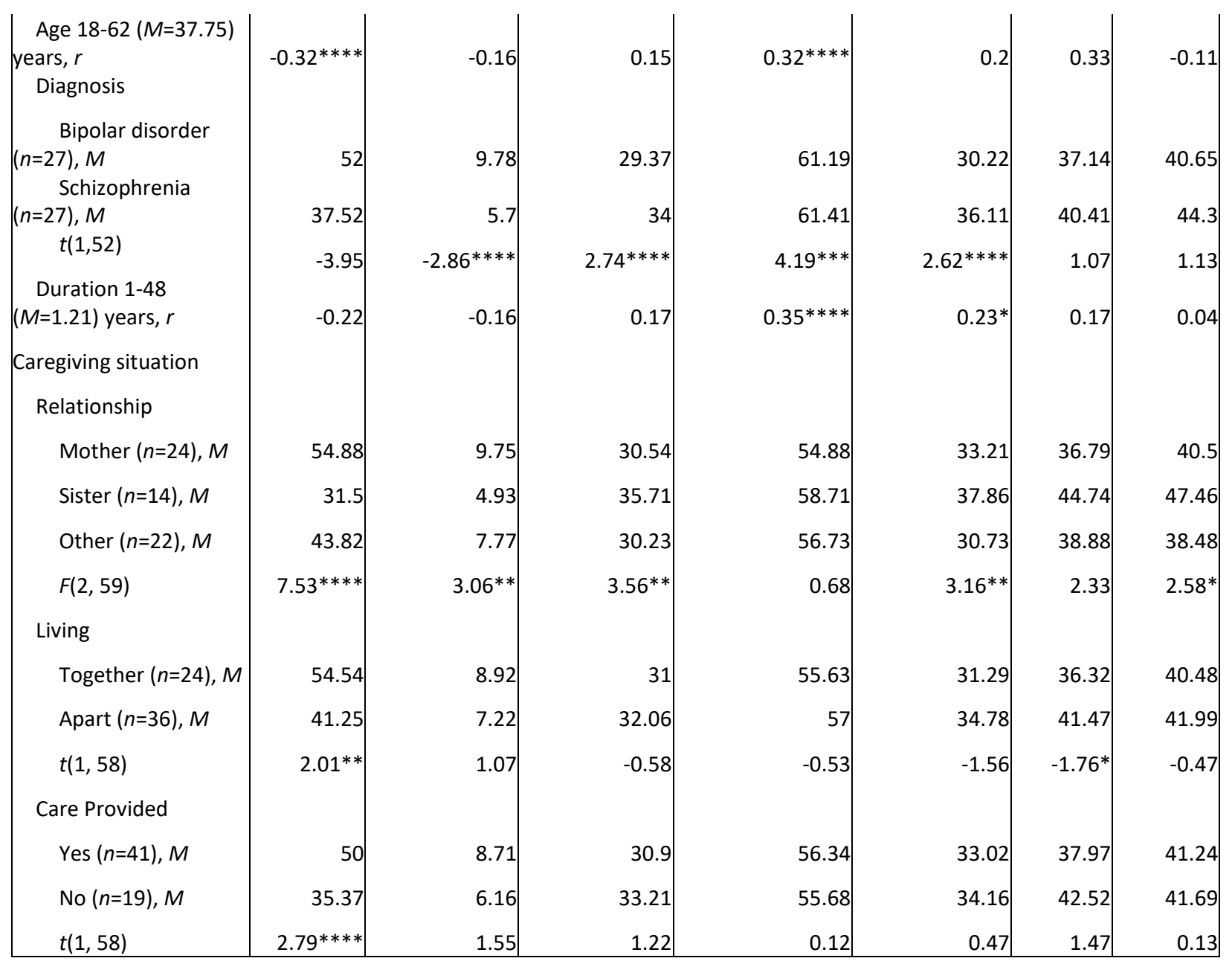

${ }^{*} p<.10 .{ }^{* *} p<.05 .{ }^{* * *} p<.01 .{ }^{* * * *} p<.001$.

care/assistance or not providing care were not associated with the family member's mental or physical health.

\section{Discussion}

This study represents a first attempt to identify the characteristics of female family members of adults with SMI, the mentally ill adults themselves, and the caregiving situation that may affect process regulators (perceived burden, stigma by association, and depressive cognitions), resourcefulness, and quality of life (physical and mental health) of the female family members. Knowledge of the associations between specific characteristics of female family members, adults with SMI, or the caregiving situation and process regulators, resourcefulness, and quality of life will help psychiatric nurses better predict which intervention strategies may be most effective for particular female family members.

\section{Characteristics of Female Family Members}

Age and level of education were not associated with burden, stigma, depressive cognitions, resourcefulness, or quality of life, but Caucasian women reported greater burden than did African American women. This is consistent with the study conducted by Haley et al. 
(2004), in which African American caregivers of people with dementia reported more benign appraisals of stress than did Caucasian caregivers of people with dementia. It has been suggested that the lower self-reported feelings of subjective burden among African American caregivers of dementia patients may reflect a perceived benefit or reward from the caregiving experience (Foley, Tung, \& Mutran, 2002; Haley et al., 2004). This may be similar in African American caregivers of seriously mentally ill family members. Folkman and Moskowitz (2000) would consider this perceived benefit or reward an important, positive, and effective mechanism for coping with stress and burden.

\section{Characteristics of Mentally III Adults}

Increasing age of the mentally ill person and more years since diagnosis were associated with lower perceived burden, greater personal resourcefulness, and better mental health of the female family member. These findings may reflect women's adaptation over time to having a seriously mentally ill family member. The findings are similar to those reported in studies of dementia caregivers, which found that with longer duration of caregiving, dementia caregivers developed resilience in adapting to their role (Gaugler, Kane, \& Newcomer, 2007). Female family members of adults with bipolar disorder expressed greater feelings of burden and stigma than did other caregivers, whereas female family members of adults with schizophrenia reported more depressive cognitions. These findings differ from those of other studies, which found that family members of persons with bipolar disorder were strikingly similar to family members of persons with schizophrenia on measures of burden (Chakrabati \& Gill, 2002; Nehra, Chakrabati, Kulhara, \& Sharma, 2005). However, the measures of burden used in those studies reflected financial burden and disruption in family routine, family leisure, and family interactions (Chakrabati \& Gill, 2002; Nehra et al., 2005). Our measure of perceived burden measured family disruption but also measured family member strain, dependence of the mentally ill person, and stigma by association.

Greater stigma by association was found in female family members of persons with bipolar disorder than family members of persons with schizophrenia, although research suggests that greater stigma is associated with a diagnosis of schizophrenia (Lake \& Hurwitz, 2006). It is possible that stigma by association is related more closely to the presence of specific symptoms or behaviors of the mentally ill person than to the actual diagnosis.

The findings from this study indicated greater personal and social resourcefulness in female relatives of adults with schizophrenia than female family members of adults with bipolar disorder. These findings differ somewhat from those of Nehra et al. (2005), who reported that coping patterns were similar in family members of persons with bipolar disorder or schizophrenia. This difference may reflect differences in measurement or in the behaviors of the mentally ill persons whose family members participated in those studies. It is also possible that female family members of adults with schizophrenia learn to be resourceful over time in relation to their mentally ill family member's behavioral symptoms. As noted above, these female family members reported lower levels of burden, perhaps because of their resourcefulness skills. 


\section{Caregiving Situation}

Female family members who were mothers of a mentally ill person experienced greater feelings of burden and stigma than did those who were sisters, daughters, or wives. This greater burden and stigma may be associated with greater involvement in providing direct care or may be attributable to feeling in some way responsible for the mental illness in their offspring (Goodman, 2004; Milliken, 2001).

Female caregivers of sisters had more depressive cognitions than did those who were mothers. At the same time, however, sisters of mentally ill persons had greater social resourcefulness than did mothers, daughters, or wives.

Not surprisingly, living together and providing care were associated with greater burden. This finding is consistent with other studies that found a positive correlation between increased activities performed by caregivers and greater caregiver burden (Faison, Faria, \& Frank, 1999). In addition, the finding is consistent with other studies which showed that inhome caregivers experienced much higher burden than did out-of-home caregivers (Cochrane, Goering, \& Rogers, 1997), and family caregivers who lived with ill relatives also experienced higher burden (Fulford \& Farhall, 2001).

\section{Summary and Implications}

The results of this study highlight the importance of examining the impact of contextual factors on perceived burden, stigma, depressive cognitions, resourcefulness, and quality of life of female family members of mentally ill adults. Women's perceptions of burden were influenced by their race/ethnicity, their relationship to the mentally ill person, the mentally ill person's age and diagnosis, and whether the women provided direct personal care. However, although women's resourcefulness was closely associated with characteristics of the mentally ill person (age, diagnosis, and years since first diagnosed), it was not associated with their own personal characteristics or factors in the family situation. In fact, the personal resourcefulness of female family members of adults with SMI appeared to increase as the mentally ill person's age and years since diagnosis increased. This is an example of possible development of resourcefulness skills over time in response to having a family member with an SMI. However, the mechanism by which these women learned resourcefulness skills is unknown and perhaps may be attributable to trial and error. Therefore, teaching personal resourcefulness skills in a more systematic way to women with newly diagnosed family members may be beneficial in maintaining their optimal quality of life.

These findings reflect the perceptions and feelings of participants at a single point in time and do not capture changes that may occur over time. Longitudinal studies of larger and more diverse samples of family members of mentally ill persons, including men, persons from additional racial/ethnic minorities, and family members of persons with a wider variety of psychiatric diagnoses, are recommended. Nevertheless, although the sample size for the study was small, the findings indicate descriptive trends that are worthy of future investigation.

The findings have direct implications for psychiatric nursing practice with women caring for family members with SMI. The findings clearly point to the importance of assessing the 
context of the caregiving/ care-providing situation for family members of the mentally ill, including characteristics of the caregiver, care recipient, and the caregiving situation itself, when planning interventions to reduce caregiver burden. More specifically, the results suggest that stress-reducing interventions might best be targeted toward Caucasian female family members who are mothers providing direct care for younger adults with bipolar disorder, because these characteristics were most strongly associated with greater burden in this study. The data also suggested that these same characteristics (Caucasian women, mothers, younger mentally ill, with bipolar disorder) were related to lower personal resourcefulness (i.e., selfhelp) skills. Thus, these women may benefit from programs that teach the cognitive-behavioral, self-help skills that constitute personal resourcefulness, because such skills have been associated with optimal quality of life (Zauszniewski, 2006).

\section{References}

American Psychiatric Association. (2000). Diagnostic and statistical manual of mental disorders (4th ed., text rev.). Washington, DC: Author.

Anglin, D. M., Link, B. G., \& Phelan, J. C. (2006). Racial differences in stigmatizing attitudes toward people with mental illness. Psychiatric Services, 57, 857-862.

Beevers, C., Wells, T., \& Miller, I. (2007). Predicting response to depression treatment: The role of negative cognition. Journal of Consulting and Clinical Psychology, 75, 422-431.

Belle, S. H., Burgio, L., Burns, R., Coon, D., Czaja, S. J., GallagherThompson, D., et al. (2006). Enhancing the quality of life of dementia caregivers from different ethnic or racial groups:A randomized controlled trial. Annals of Internal Medicine, 145, 727-738.

Biegel, D., Milligan, S. E., Putnam, P. L., \& Song, L. Y. (1994). Predictors of burden among lower socioeconomic status caregivers of persons with chronic mental illness. Community Mental Health Journal, 30, 473-494.

Chakrabati, S., \& Gill, S. (2002). Coping and its correlates among caregivers with bipolar disorder: A preliminary study. Bipolar Disorders, 4, 50-60.

Cochrane, J. J., Goering, P. N., \& Rogers, J. M. (1997). The mental health of informal caregivers in Ontario: An epidemiological survey. American Journal of Public Health, 87, 2002-2008.

Cohen, J. (1992). A power primer. Psychological Bulletin, 112, 155-159.

DeFrias, C. M., Tuokko, H., \& Rosenberg, T. (2005). Caregiver physical and mental health predicts reactions to caregiving. Aging and Mental Health, 9, 331-336.

Drentea, P., \& Goldner, M. A. (2006). Caregiving outside of the home: The effects of race on depression. Ethnicity and Health, 11, 41-57.

Faison, K. J., Faria, S. H., \& Frank, D. (1999). Caregivers of chronically ill elderly: Perceived burden. Journal of Community Health Nursing, 16, 243-253.

Fleischman, H., \& Klupp, A. (2004). Quality of life in relatives of mentally ill people. Psychiatrish Praxis, $31, \mathrm{~S} 114-\mathrm{S} 116$.

Foley, K. L., Tung, H. J., \& Mutran, E. J. (2002). Self-gain and selfloss among African American and White caregivers. The Journals of Gerontology, Psychological Sciences and Social Sciences, 57, 14-22.

Folkman, S., \& Moskowitz, J. T. (2000). Positive affect and the other side of coping. American Psychologist, 55, 647-654.

Fulford, M., \& Farhall, J. (2001). Hospital versus home care for the acutely mentally ill? Preferences of caregivers who have experienced both forms of services. Australian and New Zealand Journal of Psychiatry, 35, 619-625. 
Gaugler, J. E., Kane, R. L., \& Newcomer, R. (2007). Resilience and transitions from dementia caregiving. The Journals of Gerontology, Psychological Sciences and Social Sciences, 2, 38-44.

Gonzalez, E.W. (1997). Resourcefulness, appraisals, and coping efforts of family caregivers. Issues in Mental Health Nursing, 18, 209-227.

Gonzalez-Salvador, M. T., Arango, C., Lyketsos, C. G., \& Barba, A. C. (1999). The stress and psychological morbidity of the Alzheimer patient caregiver. International Journal of Geriatric Psychiatry, 14, 701-710.

Goodman, H. (2004). Elderly parents of adults with severe mental illness: Group work interventions. Journal of Gerontological Social Work, 44, 173-188.

Haas, B. K. (1999). A multidisciplinary concept: Analysis of quality of life. Western Journal of Nursing Research, 21, 728-742.

Haley,W. E., Gitlin, L. N.,Wisniewski, S. R., Mahoney, D. F., Coon, D.W., Winter, L., et al. (2004). Wellbeing, appraisal, and coping in African American and Caucasian dementia caregivers: Findings from the REACH study. Aging \& Mental Health, 8, 316-329.

Keir, S. T., Guill, A. B., Carter, K. E., Boole, L. C., Gonzales, L., \& Friedman, H. S. (2006). Differential levels of stress in caregivers of brain tumor patients-observations from a pilot study. Supportive Care in Cancer, 14, 1258-1261.

Kohn-Wood, L. P., \& Wilson, M. N. (2005). The context of caretaking in rural areas: Family factors influencing the level of functioning of seriously mentally ill patients living at home. American Journal of Community Psychology, 36, 1-13.

Lake, C. R., \& Hurwitz, N. (2006). Schizoaffective disorders and psychotic mood disorders: There are no schizoaffective disorders. Psychiatry Research, 143, 255-287.

Lu, Y. F., \& Wykle, M. (2007). Relationships between caregiver stress and self-care behaviors in response to symptoms. Clinical Nursing Research, 16, 29-43.

Luo, X., Lynn-George, M., Kakouras, I., Edwards, C. L., Pietrobon, R., Richardson, W., et al. (2003). Reliability, validity, and responsiveness of the short form 12-item survey (SF-12) in patients with back pain. Spine, 28, 1739-1745.

McCullagh, E., Brigstocke, G., Donaldson, N., \& Kalra, L. (2005). Determinants of caregiver burden and quality of life in caregivers of stroke patients. Stroke, 36, 2181-2186.

McCusker, J., Latimer, E., Cole, M., Ciampi, A., \& Sewitch, M. (2007). Major depression among medically ill elders contributes to sustained poor mental health in their informal caregivers. Age and Ageing, 36, 400-406.

Milliken, P. J. (2001). Disenfranchised mothers: Caring for an adult child with schizophrenia. Health Care for Women International, 22, 149-166.

Müller-Nordhorn, J., Roll, S., \& Willich, S.N. (2004). Comparison of the short form (SF)-12 health status instrument with the SF-36 in patients with coronary heart disease. Heart, 90, 523-527.

Nadler, A. (1990). Help-seeking behavior as a coping resource. In M. Rosenbaum (Ed.), Learned resourcefulness: On coping skills, self-control, and adaptive behavior. New York: Springer.

Nehra, R., Chakrabati, S., Kulhara, P., \& Sharma, R. (2005). Caregiver coping in bipolar disorder and schizophrenia: A reexamination. Social Psychiatry and Psychiatric Epidemiology, 40, 329-336.

Nelson, C. (2006). Of eggshells and thin-skulls: A consideration of racism-related mental illness impacting black women. International Journal of Law and Psychiatry, 29, 112-136.

Papastavrou, E., Kalokerinou, A., Papacostas, S. S., Tsangari, H., \& Sourtzi, P. (2007). Caring for a relative with dementia: Family caregiver burden. Journal of Advanced Nursing, 58, 446-457.

Perlick, D. A., Miklowitz, D. J., Link, B. G., Struening, E., Kaczynski, R., Gonzalez, J., et al. (2007). Perceived stigma and depression among caregivers of patients with bipolar disorder. British Journal of Psychiatry, 190, 535-536. 
Pinquart, M., \& Sorensen, S. (2005). Ethnic differences in stressors, resources, and psychological outcomes of family caregivers: A meta-analysis. The Gerontologist, 45, 90-106.

Pinquart, M., \& Sorensen, S. (2007). Correlates of physical health of informal caregivers: A meta-analysis. The Journals of Gerontology, Psychological Sciences and Social Sciences, 62, 126-137.

Raina, P., McIntyre, C., Zhu, B., McDowell, I., Santaguida, L., Kristjansson, B., et al. (2004). Understanding the influence of the complex relationships among informal and formal supports on the wellbeing of caregivers of persons with dementia. Canadian Journal on Aging, 23, 49-59.

Rosenbaum, M. (1990). Learned resourcefulness on coping skills, self-control, and adaptive behavior. New York: Springer. Rosswurm, M. A., Larrabee, J. H., \& Zhang, J. (2002). Training family caregivers of dependent elderly adults through on-site and telecommunication programs. Journal of Gerontological Nursing, 28, 27-38.

Salyers, M., Bosworth, H., \& Swanson, J. (2000). Reliability and validity of the SF-12 Health Survey among people with severe mental illness. Medical Care, 38, 1141-1150.

Sapnas, K. G., \& Zeller, R. A. (2002). Minimizing sample size when using exploratory factor analysis for measurement. Journal of Nursing Measurement, 10, 135-154.

Savage, S., \& Bailey, S. (2004). The impact of caring on caregivers' mental health: A review of the literature. Australian Health Review, 27, 111-117.

Serrano-Aguilar, P. G., Lopez-Bastida, J., \& Yanes-Lopez, V. (2006). Impact on health-related quality of life and perceived burden of informal caregivers of individuals with Alzheimer's disease. Neuroepidemiology, 27, 136-142.

Sibitz, I., Amering, M., Kramer, B., Griengl, H., \& Katschnig, H. (2002). The course of illness and problems of schizophrenic women and men from the relatives' perspective. Psychiatrish Praxis, 29, 148153.

Steadman, P. L., Tremont, G., \& Davis, J. D. (2007). Premorbid relationship satisfaction and caregiver burden in dementia caregivers. Journal of Geriatric Psychiatry and Neurology, 20, 115-119.

Stengard, J. (2002). Caregiving types and psychosocial well-being of caregivers of people with mental illness in Finland. Psychiatric Rehabilitation Journal, 26, 154-164.

Takano, M., \& Arai, H. (2005). Gender differences and caregivers' burden in early onset Alzheimer's disease. Psychogeriatrics, 5, 73.

Tsang, H., Tam, P., Chan, F., \& Cheung, W. (2003). Sources of burden on families of individuals with mental illness. International Journal of Rehabilitation Research, 26, 123-130.

Tung, W. C., \& Gillett, P. A. (2005). Stages of change for physical activity among family caregivers. Journal of Advanced Nursing, 49, 513-521.

U.S. Department of Health and Human Services. (2003). President's New Freedom Commission on Mental Health: Achieving the promise: Transforming mental health care in America, final report (DHHS Publication No. SMA-03-3832). Rockville, MD: Department of Health and Human Services, U.S. Public Health Service.

Veltman, A., Cameron, J., \& Stewart, D. E. (2002). The experience of providing care to relatives with chronic mental illness. Journal of Nervous and Mental Disease, 190, 108-114.

Ware, J. E., Kosinski, M., \& Keller, S. D. (1996). A 12-item Short Form Health Survey (SF-12): Construction of scales and preliminary tests of reliability and validity. Medical Care, 32, 220-233.

Williams, I. C. (2005). Emotional health of black and white dementia caregivers: A contextual examination. The Journals of Gerontology, Psychological Sciences and Social Sciences, 60, 287295.

Wittmund, B., Wilms, U., Mory, C., \& Angermeyer, M. C. (2002). Depressive disorders in spouses of mentally ill patients. Social Psychiatry and Psychiatric Epidemiology, 37, 177-182.

Wynaden, D., Ladzinski, U., Lapsley, J., Landsborough, I., Butt, J., \& Hewitt, V. (2006). The caregiving experience: How much do health professionals understand? Collegian, 13, 6-10. 
Zauszniewski, J. A. (1995). Development and testing of a measure of depressive cognitions in older adults. Journal of Nursing Measurement, 3, 31-41.

Zauszniewski, J. A. (1997). The Depressive Cognition Scale: Further psychometric evaluation. Journal of Nursing Measurement, 5, 191-200.

Zauszniewski, J. A. (2006). Resourcefulness. In J. J. Fitzpatrick \& M. Wallace (Eds.), Encyclopedia of nursing research (pp. 256-258). New York: Springer.

Zauszniewski, J. A., Lai, C. Y., \& Tithiphontumrong, S. (2006). Development and testing of the resourcefulness scale for older adults. Journal of Nursing Measurement, 14, 57-68.

Zauszniewski, J.A., McDonald, P. E., Krafcik, K., \& Chung, C. (2002). Acceptance, cognitions, and resourcefulness in women with diabetes. Western Journal of Nursing Research, 24, 728-743.

Zauszniewski, J. A., Picot, S. J., Roberts, B. L., Debanne, S. M., \& Wykle, M. L. (2005). Predictors of resourcefulness in African American women. Journal of Aging and Health, 17, 609-633. 